\title{
Formação de Professores de Matemática em Licenciaturas em Educação do Campo: entre cartas, epistemologias e currículos
}

\author{
Mathematics Teachers Training in Rural Education Graduation Courses: \\ letters, epistemologies and curriculums
}

Filipe Santos Fernandes*

ORCID iD 0000-0002-2964-3582

\begin{abstract}
Resumo
Este trabalho busca problematizar a formação de professores de Matemática em Licenciaturas em Educação do Campo. Para isso, discutimos questões epistemológicas e curriculares que se situam no deslocamento de uma formação disciplinar, aquela que toma a Matemática como a reunião de um conjunto de saberes historicamente construídos e consolidados pela comunidade científico-acadêmica dos matemáticos, para uma formação por áreas de conhecimento, proposta e desafio colocado às Licenciaturas em Educação do Campo. Junto a narrativas produzidas por alunos da habilitação em Matemática do curso de Licenciatura em Educação do Campo, da UFMG, a partir de um projeto de ensino que envolvia a escrita de cartas, apresentamos considerações sobre como as dimensões da formação por áreas do conhecimento, bem como as dinâmicas de um curso em alternância, desdobram-se em aspectos formativos que, para além de uma abordagem disciplinar, envolvem modos de estar, de conhecer e de ser que rompem com epistemologias e currículos tradicionalmente estabelecidos nos cursos de formação de professores de Matemática.
\end{abstract}

Palavras-chave Áreas de Conhecimento. Educação do Campo. Educação Matemática. Etnomatemática. Formação de Professores de Matemática.

\begin{abstract}
This work aims to problematize mathematics teachers training in Rural Education graduation courses. In order to achieve this, we discussed epistemological and curricular questions that are in the displacement of a disciplinary training, the one that takes mathematics as the gathering of a set of knowledge historically constructed and consolidated by the mathematics scientific-academic community, for a training by area of knowledge, proposal and challenge placed to the Rural Education graduation courses. With the narratives produced by mathematics graduation students from a Rural Education course in a teaching project involving the elaboration of letters, we presented considerations about the dimensions of a training by areas of knowledge. Also, the dynamics of a course in alternation unfold in formative aspects that, in addition to a disciplinary approach, involve ways of being and knowing that break with epistemologies and curriculums traditionally established in mathematics teachers training courses.
\end{abstract}

Keywords: Areas of Knowledge. Rural Education. Mathematics Education. Ethnomathematics. Mathematics teachers training.

\footnotetext{
* Doutor em Educação Matemática pela Universidade Estadual Paulista "Júlio de Mesquita Filho" (UNESP/Rio Claro). Professor da Faculdade de Educação da Universidade Federal de Minas Gerais (UFMG), Belo Horizonte, Minas Gerais, Brasil. Membro do Grupo de Pesquisa História Oral e Educação Matemática (GHOEM) e do Núcleo de Estudos e Pesquisas em Educação do Campo (NEPCampo). Endereço para correspondência: Av. Antonio Carlos, 6627, Pampulha, Belo Horizonte, Minas Gerais, Brasil, CEP: 31270-901. E-mail: fernandes.fjf@gmail.com.
} 


\section{Introdução}

Este trabalho tem a intenção de problematizar a formação de professores de Matemática em Licenciaturas em Educação do Campo a partir da perspectiva da formação por áreas de conhecimento (MOLINA, 2015).

Junto a narrativas de alunos da habilitação em Matemática do curso de Licenciatura em Educação do Campo da Universidade Federal de Minas Gerais (UFMG), produzidas em um projeto de ensino de uma disciplina ministrada no primeiro semestre do curso, apresentamos considerações sobre como a formação por áreas do conhecimento, bem como as dinâmicas de um curso em alternância ${ }^{1}$, desdobra-se em modos de estar, de conhecer e de ser que rompem com as lógicas tradicionalmente estabelecidas nos cursos de Licenciatura em Matemática.

Para apresentar tais considerações, o texto segue por três movimentos. No primeiro, discutimos questões epistemológicas da formação de professores de Matemática que se situam no deslocamento de uma formação disciplinar, aquela que toma a Matemática como a reunião de um conjunto de saberes historicamente construídos e consolidados pela comunidade científico-acadêmica dos matemáticos e que é usualmente praticada na Licenciaturas em Matemática, para uma formação por áreas de conhecimento, proposta e desafio colocado às Licenciaturas em Educação do Campo.

No segundo, apresentamos o contexto de uma disciplina que teve como orientação principal a formação por áreas de conhecimento, colocando suas ideias a serviço da produção de sentidos para a educação, para a escola, para o campo e para o modo de vida camponês. Finalmente, no terceiro, especialmente sensibilizados pelas narrativas produzidas pelos alunos durante a realização de uma disciplina, levantamos compreensões que envolvem modos de estar, de conhecer e de ser junto ao curso.

Esperamos que este texto contribua não só com discussões ligadas à Licenciatura em Educação do Campo, mas que permita pensar de um modo geral a formação por áreas de conhecimento, insinuando questões e propostas epistemológicas e curriculares para a formação de professores que ensinam Matemática.

\footnotetext{
${ }^{1} \mathrm{O}$ curso de Licenciatura em Educação do Campo da UFMG adota a Pedagogia da Alternância como princípio e sistema formativo. A valorização da Pedagogia da Alternância surge como meio de fortalecer os modos de vida campesinos, especialmente a agricultura familiar, tornando-a um caminho na elaboração de propostas curriculares a serem seguidas pelas escolas do campo e pelos cursos de formação de professores.
} 


\section{Da disciplina à área de conhecimento: pontuando questões epistemológicas}

O curso de Licenciatura em Educação do Campo da Universidade Federal de Minas Gerais articula-se em torno de quatro áreas de conhecimento: Línguas, Artes e Literatura; Ciências da Vida e da Natureza; Ciências Sociais e Humanidades e Matemática. Traçando uma breve consideração a partir das denominações das áreas, poderíamos supor que as três primeiras apresentam como marca o rompimento com a ideia de disciplinarização, ao passo que a última, a Matemática, ainda parece conservar tal característica.

Ainda nessa breve consideração, dificilmente seria possível supor práticas formativas que estejam além de um contorno disciplinar já estabelecido no espaço científico-acadêmico e praticado, especialmente, nos tradicionais cursos de Licenciatura em Matemática do país. Contudo, na aproximação da formação de professores de Matemática com a Educação do Campo novas educabilidades são disparadas, sendo necessário recolocar questões epistemológicas e curriculares para que não haja confusão entre esses dois modos de pensar e praticar a formação de professores: a formação disciplinar e a formação por área de conhecimento.

Historicamente, a formação de professores de Matemática no Brasil tem sido marcada pelo papel periférico dos saberes pedagógicos nos currículos e pelo distanciamento com questões relativas à educação escolar. Gomes (2016) destaca que em oitenta anos de criação do primeiro curso de Matemática do Brasil pouco se avançou na superação de tal marca: nesses cursos, foca-se o desenvolvimento da pesquisa em Matemática, assumindo a formação de professores um papel notoriamente menor. Está em jogo, assim, uma formação disciplinar na qual a Matemática resume-se a um conjunto de saberes historicamente construídos e consolidados pela comunidade científico-acadêmica dos matemáticos; saberes que, em geral, têm como direção o desenvolvimento científico e tecnológico e que dão centralidade à vida em uma sociedade urbano-industrial.

Esse modo de pensar a formação de professores tem, evidentemente, laços com questões epistemológicas mais amplas que envolvem a própria Matemática. Ao se converter como metanarrativa da modernidade (CLARETO, 2003), a Matemática recebe um estatuto universalizante que viabiliza a normalização de modos de pensar, de fazer e de ser. Assim, prevalece na formação de professores "um modo de pensar e fazer matemática que busca e valoriza a clareza da linguagem, a objetividade, a certeza, o recurso a demonstrações, a generalidade das proposições, a segurança e a perenidade do que se assegura como o conhecimento matemático" (SOUZA; FONSECA, 2010, p. 306). Esses elementos 
desdobram-se em modos de ser na medida em que propõem a Matemática como linguagem e procedimento fundamental da ciência, da razão e da verdade, forma legítima de significar o mundo. Nas palavras de D'Ambrosio (2002, p. 17):

a Matemática, com seu caráter de infalibilidade, de rigor, de precisão e de ser um instrumento essencial e poderoso no mundo moderno, teve sua presença firmada excluindo outras formas de pensamento. Na verdade, ser racional é identificado com dominar a Matemática. A Matemática se apresenta como um deus mais sábio, mais milagroso e mais poderoso que as divindades tradicionais e outras tradições culturais.

Esse paradigma epistemológico abriu caminhos para o estabelecimento de cenários de formação de professores de Matemática nos quais o fundamental é o domínio dos conteúdos da Matemática acadêmica, mesmo sem explicitar mais precisamente seu papel ou contribuição na/para a formação docente. Essa postura faz parte de um projeto maior que tem em seu núcleo a dominação e a subordinação de certas formas de pensamento e a preparação de sujeitos para a vida em uma sociedade marcada pelo desejo de progresso creditado ao desenvolvimento científico e tecnológico.

Trata-se, então, de um projeto que não se consolida apenas nas práticas formativas de professores, mas que se efetiva em práticas educativas escolares e universitárias que prescrevem e promovem a individualização do pensamento; a especificação e a hierarquização de saberes; a naturalização da seriação, da mecanização e da memorização nos processos de ensino-aprendizagem; e a adaptação da lógica de produção, de avaliação e de gratificação da vida capitalista ao espaço escolar.

Contudo, a Educação do Campo, ao trazer para a formação de professores a perspectiva de área do conhecimento, busca romper o paradigma epistemológico acima descrito. Nas palavras de Molina (2015, p. 153):

\begin{abstract}
a formação por áreas de conhecimento deve desenvolver-se tendo como intencionalidade maior promover estratégias que contribuam para superar a fragmentação do conhecimento, criando, propondo e promovendo ações docentes articuladas interdisciplinarmente, associadas intrinsecamente às transformações no funcionamento da escola e articuladas, ainda, às demandas da comunidade rural na qual se insere esta escola. A proposta e o desafio é realmente materializar práticas formativas durante o percurso da Licenciatura em Educação do Campo que sejam capazes de ir desenvolvendo e promovendo nos futuros educadores as habilidades necessárias para contribuir com a consolidação do ideal de escola edificado por este movimento educacional protagonizado pelos camponeses nestes últimos 15 anos: uma Escola do Campo.
\end{abstract}

A partir do excerto, podemos identificar que a proposta de uma formação por áreas de conhecimento visa, por um lado, esgarçar as fronteiras disciplinares que se direcionam a conhecimentos próprios do espaço científico-acadêmico ou da cultura urbano-industrial e, por outro, problematizar o espaço que essas disciplinas ocupam na educação escolar do campo. 
Seja no desmantelamento ou no alargamento de fronteiras, uma pergunta surge como natural aos processos de formação de professores de Matemática: nas novas perspectivas epistemológicas e curriculares insinuadas pelas áreas de conhecimento, especialmente nas Licenciaturas em Educação do Campo, como situar os conceitos, procedimentos e linguagens do que entendemos, hoje, por Matemática?

Em torno dessa questão, poderíamos, por exemplo, aproximar a Matemática das chamadas Ciências da Vida e da Natureza, já que, historicamente, o conhecimento do mundo natural e da vida auxiliou na construção de objetos matemáticos ou foi de algum modo por eles perpassado. Poderíamos, ainda, defender a Matemática como linguagem e situá-la ao lado das discussões que envolvem a Língua, a Arte ou a Literatura. Ocorre que, qualquer que seja a posição tomada, parece-nos fundamental revisitar os currículos de nossas Licenciaturas, especialmente das práticas educativas que os compõem.

Ainda que pudéssemos seguir, como nos exemplos acima, em aproximações e distanciamentos, optamos por pensar a Matemática como uma área de conhecimento sem recorrer à aglutinação de campos disciplinares já consolidados. Junto à Molina (2015), sugerimos que a formação por áreas de conhecimento nas Licenciaturas em Educação do Campo dê centralidade a discussões epistemológicas e curriculares que problematizem os modos pelos quais esse conhecimento pode romper com as lógicas urbanocêntrica e do ruralismo pedagógico que permeiam a educação escolar.

Especialmente no âmbito da Matemática, tomá-la como área de conhecimento supõe romper com dimensões universalizantes que delimitam seu contorno disciplinar, tomando-a como uma produção humana, socioculturalmente situada e que, especialmente em situações campesinas, dissipa as características de infalibilidade, de rigor e de precisão e de instrumento poderoso do mundo moderno que foram historicamente a ela atribuídas. No limite, o que esses rompimentos propõem são novas dimensões que desenham elementos curriculares que envolvem modos próprios de saber, de fazer e, fundamentalmente, de ser.

\footnotetext{
As contribuições da matemática como área de conhecimento no contexto da contemporaneidade como algo que auxilia a identidade dos sujeitos do campo precisam ser discutidas, planejadas e aplicadas no cotidiano das escolas do campo em constante e produtivo diálogo com outras áreas e contextos de produção de conhecimento (AUAREK; PAULA, 2016, p. 41).
}

A perspectiva das áreas de conhecimento, ainda que recentemente explorada para tratar de questões da formação de professores de Matemática, lança uma série de desafios: o que significa, no âmbito epistemológico, pensar a Matemática como uma área de conhecimento? Como pensar espaços formativos e desenhos curriculares nos quais a 
disciplina de Matemática, usualmente fundamentada na fragmentação do conhecimento e estabelecida como metanarrativa da modernidade, dê lugar a discussões que envolvam a Matemática como área de conhecimento, meio de transformação da educação articulado às demandas do campesinato? Como estabelecer estratégias de ensino que esgarcem as fronteiras disciplinares e tomem a formação de professores de Matemática a serviço da vida e da superação das marcas de desigualdade e injustiça ainda presentes no campo brasileiro?

É nas cercanias dessas questões que apresentamos a seguir considerações decorrentes de uma disciplina oferecida para alunos da habilitação em Matemática do curso de Licenciatura em Educação do Campo da UFMG, em 2016. A proposta é perceber como as ideias da formação por áreas de conhecimento, ao serem colocadas em funcionamento em uma disciplina do currículo, bem como as dinâmicas de um curso em alternância, possibilitaram tecer modos de estar, de conhecer e de ser dos alunos do curso, rompendo com as dimensões disciplinares da Matemática pautadas - como já apresentamos - em aspectos como a individualização do pensamento, a hegemonia de certos saberes e a adaptação da lógica da vida capitalista à escola, em tempos e espaços.

\section{A área de conhecimento em funcionamento: pontuando questões curriculares}

No primeiro semestre do curso de Licenciatura em Educação do Campo, habilitação em Matemática, da UFMG, os licenciandos cursam a disciplina Estudo dos Números Naturais. Essa disciplina tem como objetivo levar o aluno a compreender os sentidos e usos dos números naturais em nossa vida, bem como pensar educabilidades, estratégias e recursos didáticos direcionados a processos de ensino-aprendizagem em ambientes escolares. Assim, prevalece, no percurso da disciplina, não apenas questões científico-acadêmicas ${ }^{2}$ relativas aos números naturais - como axiomas, propriedades, operações etc. -, mas também questões que tocam os desdobramentos desses números no modo como significamos e intervimos no mundo, em uma dimensão sociocultural que dá centralidade a saberes e fazeres geralmente negligenciados pelo espaço científico-acadêmico.

No período do Tempo Escola ${ }^{3}$, realizado em julho e agosto de 2016, foram realizados

\footnotetext{
2 Adotaremos neste texto a adjetivação científico-acadêmico para fazer referências aos saberes e fazeres usualmente praticados nos espaços de formação de professores, especialmente nos ambientes universitários centrados na formação disciplinar. Em oposição, tomaremos o termo populares para designar saberes e fazeres que são excluídos das dinâmicas de produção do conhecimento tanto na universidade quanto na escola.

${ }^{3}$ No caso da UFMG, a Pedagogia da Alternância funciona em dois tempos: o Tempo Escola, momento em que os alunos estão presencialmente na Universidade para um conjunto de atividades; e o Tempo Comunidade,
} 
oito encontros presenciais com quatro horas de duração cada. Nesses encontros, visando trazer para a disciplina a perspectiva da formação por área de conhecimento, empreendemos discussões que tomam a Matemática como uma produção humana, socioculturalmente situada; que examinam o currículo de Matemática das escolas do campo, enfatizando a possibilidade de superação de lógicas urbanocêntricas; e que exploram as possibilidades e os limites da etnomatemática na educação escolar do/no campo.

Vale destacar, aqui, o importante papel desempenhado pela perspectiva etnomatemática que alicerçou o desenvolvimento da disciplina. Segundo D’Ambrósio (2002, p. 14), etnomatemática é "a arte ou técnica (techné = tica) de explicar, de entender, de se desempenhar na realidade (matema), dentro de um contexto cultural próprio (etno)". A etnomatemática busca entender, analisar e valorizar os saberes e os fazeres produzidos nas tramas relacionais de diferentes grupos socioculturais ${ }^{4}$. Nesse sentido, a etnomatemática

incorpora o estudo da matemática produzida pelos mais diferentes grupos sociais, e muitos desses grupos estão vinculados ao campo brasileiro. Assim, é possível encontrarmos pesquisas que buscam descrever as práticas sociais e as racionalidades matemáticas que as sustentam, originárias de agricultores, quilombolas, ribeirinhos, pescadores, entre outros (DUARTE, 2014, p. 22).

Assim, no processo formativo em curso, os saberes populares e os científicoacadêmicos não se opunham, mas participavam juntos e de forma qualificada visando à compreensão e à valorização por parte dos alunos dos saberes de sua cultura, sem negligenciar o acesso aos saberes historicamente construídos e difundidos pela sociedade capitalista, urbana, industrial, científica e tecnológica da qual inevitavelmente participamos. Optamos por trabalhar em uma região fronteiriça que buscava na experiência de contato entre esses saberes a produção de sentidos para a educação, para a escola, para o campo e para o modo de vida camponês.

Ao final dos oito encontros presenciais, apresentamos uma proposta de trabalho para o Tempo Comunidade, que também contou com a direção da perspectiva etnomatemática assumida acima. Propusemos aos alunos que respondessem a uma carta que lhes foi entregue no último dia de aula. Nela, ponderamos sobre sua participação no primeiro Tempo Escola do curso, levantamos brevemente as discussões realizadas nos encontros da disciplina e pedimos que, a partir dessas discussões, observassem em sua comunidade questões ligadas à Matemática. A íntegra da carta encontra-se a seguir.

momento em que os alunos retornam a suas localidades com questões, atividades e propostas de intervenção.

${ }^{4}$ Poderíamos considerar, aqui, diferentes entendimentos sobre a etnomatemática. Contudo, acreditamos que a abordagem dada por Ubiratan D'Ambrosio, ainda que pontualmente apresentada neste texto, era suficiente para a elaboração de orientações metodológicas naquele momento da disciplina. 
Belo Horizonte, 4 de agosto de 2016.

Querido aluno, querida aluna.

Sei que no dia 4 de julho deste ano uma nova fase começou na vida de vocês. Iniciar uma graduação não é fácil: conhecer novas ideias e conceitos; ficar longe da família, dos filhos, de nossa casa, do trabalho; passar por bons e por dificeis momentos; aprender a conviver com colegas de universidade, de discussões, de atividades e até mesmo de quarto! Tudo isso em um mês intenso de estudo e trabalho!

No curso, discutimos que existem matemáticas que se aproximam e se distanciam daquela matemática que tanto exclui e segrega. Vimos que produzimos matemáticas singulares em diferentes contextos socioculturais. Defendemos o cuidado e a atenção a essas matemáticas, bem como o respeito e a valorização do outro e de seus saberes e fazeres. Sentimos que fazemos parte disso, como professores e professoras de contextos campesinos...

Gostaria, porém, de conhecer um pouco mais sobre você, sobre sua trajetória, sobre sua comunidade e sobre o modo como você, futuro professor de matemática atento às questões do campo, observa as práticas matemáticas que lhe rodeiam. Por isso, peço que me respondam esta carta, contando como, em alguma prática de sua comunidade, aparecem saberes matemáticos que podem ou não se aproximar daqueles que aprendemos nos bancos da escola ou da universidade. Conversem com pessoas, visitem lugares, escutem os mais velhos, observem e relatem. Quero conhecer o campo que vivem, já que existem tantos por aí...

Foi um prazer estar com vocês nesses dias. Espero que tenham um bom retorno.

Um grande abraço!

Filipe.

O objetivo dessa ação pedagógica era dispor três aprendizagens, fundamentalmente: permitir aos alunos uma pesquisa junto às comunidades, descrevendo suas características sociais e culturais; promover uma pesquisa histórica, ainda que não delineada em cuidados historiográficos, sobre sua comunidade e a própria Matemática; e desdobrar-se em uma postura pedagógica atenta aos saberes de um determinado grupo sociocultural.

Passados dois meses, os alunos, em um novo encontro presencial realizado na UFMG, entregaram suas cartas. Diferentes envelopes chegaram às nossas mãos. Variados tipos de papel e bordados de letras compunham escritos intensamente comprometidos com a nossa proposta; uma proposta que, aliás, ganhou novos contornos. Inicialmente como um projeto de ensino, a leitura das cartas permitia-nos elaborar compreensões mais sensíveis sobre diferentes aspectos da formação naquele momento inicial do curso, potencializando nossas inquietações sobre os processos formativos de professores de Matemática em cursos de Licenciatura em Educação do Campo.

Acreditamos que abordar essas dimensões é, no limite, discutir como a perspectiva da área de formação tem possibilitado a existência de um currículo para a Licenciatura em Educação do Campo voltado à formação de professores de Matemática. Aqui, o currículo não é pensado de modo a envolver e descrever conteúdos ou métodos, mas como um 
composto heterogêneo, constituído por matérias díspares e de naturezas distintas; por saberes diversos e com capacidades variadas; por sentidos múltiplos e com inúmeras possibilidades. Um currículo está sempre cheio de ordenamentos, de linhas fixas, de corpos organizados, de identidades majoritárias. Porém um currículo, também, está sempre cheio de possibilidades de rompimento das linhas do ser; de contágios que podem nascer e se mover por caminhos insuspeitados; de construção de modos de vida que podem se desenvolver de formas particulares. Um currículo é um artefato com muitas possibilidades de diálogos com a vida; com diversas possibilidades de modos de vida, de povos e de seus desejos. É um artefato com um mundo a explorar. Afinal, mesmo sendo um espaço disciplinar, por excelência, muitas coisas podem acontecer em um currículo (PARAÍSO, 2009, p. 278).

Ainda que em um espaço disciplinar, um curso sobre Estudo dos Números Naturais, buscamos delinear agenciamentos que, habitados por modos de vida, por povos e por seus desejos, percorrem três caminhos correlacionados - ou, ao menos, os três caminhos oportunos para a elaboração deste texto.

No primeiro deles, modos de estar, destacamos questões relacionadas à convivência $\mathrm{e}$ à oportunidade; no segundo, modos de conhecer, expressamos e discutimos as posições dos alunos sobre a Educação e a Matemática, relacionando-as a possibilidades curriculares tanto para o curso de Licenciatura quanto para a escola; por fim, em modos de ser, buscamos evidenciar dimensões do tornar-se professor, profissionalidades que se desenham junto a trajetórias e a diferentes afetações do curso.

\subsection{Modos de Estar}

$\mathrm{Na}$ leitura das cartas, fomos sensibilizados por diferentes modos de estar no curso em sua fase inicial. O curso de Licenciatura em Educação do Campo da UFMG, ao adotar a Pedagogia da Alternância como princípio e sistema formativo, parece dispor aos alunos relações não previstas nos tradicionais cursos de licenciatura, como a convivência com outros alunos em um hotel pelo período de cinco semanas; o encontro com uma cidade de grande porte, como Belo Horizonte; a distância da família e dos amigos e os sentimentos nela envolvidos; o retorno ao espaço escolar; a intensidade das rotinas de estudo e tantas outras pautadas nas especificidades de uma graduação que funciona na alternância de tempos e espaços. Essas relações são potencializadas no período anterior e posterior ao ingresso no curso, como lemos nas cartas das alunas Amanda e Maria Clarice:

Em um mês intenso de estudo e trabalho, também o desafio de conviver, depois de longos anos após ter concluído o Ensino Médio, em sala de aula com novos colegas, de diferentes personalidades, na universidade e principalmente no hotel no qual estávamos hospedados. (Trecho da Carta de Amanda, 2016).

Não foram fáceis todos esses dias, entrar em um curso que imaginava tão diferente de mim, 
conhecer pessoas de outras cidades, de outros costumes e de outras maneiras, conviver e socializar com gente de todos os tipos, ficar longe dos pais, do aconchego do lar, estar em uma "cidade grande" e ter apoio dos familiares e amigos apenas pelo telefone, tudo foi marcante e intenso em um único mês.

(Trecho da carta de Maria Clarice, 2016).

Não apenas as cartas, mas as diferentes convivências com esses alunos, nos levam a pensar que há nesses espaços a constituição de uma forma solidária de conviver ou, como denomina Mariasch (2010), uma solidariedade por convivência. Nesse sentido, o sujeito engaja-se em um plano coletivo por meio de diferentes agenciamentos, usuais ou não em um curso de licenciatura e, junto a eles, efetiva suas ações em torno de um projeto político. Como estabelece Mariasch (2010, p. 166): “o ser não apenas vive, ele 'con-vive, vive-com', dando ao conceito de 'solidariedade' uma conotação que vai além da cooperação e a participação: a solidariedade torna-se constitutiva, ontológica". A solidariedade por convivência estabelecida pelos alunos ganha, então, não só um sentido físico - conviver em um mesmo espaço por um longo período -, mas subjetivo que procura romper com as individualidades que marcam os convívios nos espaços científico-acadêmicos tradicionais: o coletivo como dimensão constituída e constituinte no curso.

O conhecimento adquirido no coletivo liberta, colocando os coletivos em condições de uma vida autônoma, produtiva, digna e criativa, guiada pelas paixões alegres, para enlaçar-se com outros coletivos e intercambiar seus conhecimentos de modo a potenciar-se e expandir-se constantemente, afirmando sua força constituinte (MARIASCH, 2010, p. 181-182).

Além dessa dimensão da solidariedade por convivência, que diz de uma implicação do estar no ser movida, sobretudo, pelas especificidades da Pedagogia da Alternância, destaca-se em algumas cartas uma importante e politicamente preocupante característica do curso: a formação de professores do campo parece profundamente marcada pelo signo da oportunidade. Em diferentes momentos, as cartas evidenciam o curso como a única oportunidade dada aos alunos de frequentar o Ensino Superior. Ainda que vista em uma dimensão positiva, o signo da oportunidade que marca a formação de professores nas Licenciaturas em Educação do Campo denuncia a carência de políticas públicas de acesso e permanência dos grupos campesinos em espaços universitários.

Realmente no dia 4 de julho começou uma nova fase em minha vida. Surgiu a grande oportunidade de iniciar uma graduação, apesar de que esse não era o curso que eu sonhava fazer, mas depois de tentar o ENEM várias vezes consecutivas, em busca de ingressar em um curso de Medicina Veterinária, eu optei por me inscrever no LECAMPO, no qual estou muito feliz.

(Trecho da carta de Lucina, 2016).

Foi bem turbulenta aquela semana [da divulgação do resultado do vestibular], a ansiedade e o desespero tomaram conta de mim, não sabia como fazer com meu filho, se seria possível 
agarrar a oportunidade da tão sonhada graduação!

(Trecho da carta de Amanda, 2016).

Outro elemento presente nas cartas refere-se ao contato e ao envolvimento inicial dos alunos com práticas do curso que escapam aos espaços da sala de aula, como os momentos coletivos $^{5}$ que congregam estudantes das diferentes habilitações em discussões e sobre temas atuais da Educação do Campo - como organicidade, princípios e práticas da/na educação escolar do campo, questão agrária brasileira, conjuntura político-educacional do país etc. - e a mística, ato simbólico e performático organizado pelos alunos e que, tendo como origem os movimentos sociais, visa contribuir com o processo formativo em um sentido crítico e atento às diferentes lutas que afirmam a educação e a vida campesina. Um modo de estar nessas práticas é descrito por Eliziara em sua carta:

Realmente, o primeiro Tempo Escola foi intenso. Iniciamos a formação das primeiras amizades, pequenos grupos, nesse grande grupo que parece também uma nova família. Fiquei emocionada com a receptiva, pois acredito que participo da luta dos povos do campo que amam o curso. Não imaginava que haveria esse tempo para apresentar os movimentos sociais, suas bandeiras e a luta pela terra. Conheci movimentos novos e me senti integrada a eles. Tive a sensação de que minha luta se somava a de muitos [...]

(Trecho da carta de Eliziara, 2016).

Junto às narrativas dos alunos, podemos considerar que os modos de estar no curso são permeados de sentidos ligados à solidariedade por convivência, à oportunidade de ingresso e permanência no Ensino Superior e aos encontros produzidos pelos momentos coletivos do curso. A Matemática como uma área de conhecimento, fortalecida pela pedagogia da alternância, parece, então, romper com o imperativo que firma a individualidade da produção do conhecimento, cultivando a importância de desenhos curriculares pautados na coletividade, em um processo solidário de negociação que, intencionalmente, direciona-se a um horizonte comum: o estar como tornar-se presença em um coletivo que pensa a educação aliada às demandas do campo e de seus espaços escolares.

\subsection{Modos de Conhecer}

Orientados pela perspectiva etnomatemática que fundamentou a disciplina, pedimos aos alunos que descrevessem saberes identificados por eles como matemáticos em suas comunidades. Esperávamos com esse pedido que os licenciados observassem situações dentro

\footnotetext{
${ }^{5}$ Atualmente, os alunos cursam, em todos os semestres, a disciplina Processos de Ensino e Aprendizagem. O objetivo geral da disciplina é discutir questões de organicidade e de articulação dos processos pedagógicos do Tempo Escola e do Tempo Comunidade.
} 
e/ou fora da escola nas quais figurassem suas compreensões sobre o conhecimento matemático, fazendo evidenciar "as diferenças localizadas no espaço e no instante" (CLARETO, 2009, p.130-131). Interessa-nos uma dimensão epistemológica que permitisse esgarçar, multiplicar, confrontar e romper com compreensões sobre o conhecimento matemático, indicando caminhos outros para os processos formativos de professores de Matemática.

Em um plano geral, os alunos buscaram em práticas laborais de membros das comunidades elementos usualmente reconhecidos como matemáticos, como modos de contar, de calcular, de medir e de classificar próprios de suas comunidades. Acreditamos que essa opção dos estudantes está sustentada em suas trajetórias escolares com a Matemática, na qual os saberes ligados à contagem, ao cálculo, à medição e à classificação figuram mais intensamente. Nesse aspecto, podemos destacar, dentre outras leituras, as cartas de Maria Clarice, Israel e Gabriel:

Analisando algumas práticas matemáticas dentro da minha comunidade, prestei bastante atenção no trabalho dos meus pais, que são agricultores familiares e trabalham na produção do polvilho. Eles usam medidas chamadas "litro", "prato" e "quarta". Os 72 litros de polvilho ou 24 pratos correspondem a um saco de $50 \mathrm{~kg}$. 1 prato corresponde a três litros e 12 pratos correspondem a uma quarta, que é o mesmo que meio saco de polvilho.

(Trecho da carta de Maria Clarice, 2016).

Depois dos primeiros dias de curso, percebi que em minha cidade existem muitas matemáticas, e algumas me chamam a atenção. São elas: a medição da goma, que é medida por "prato"; o "metro" da areia, que são seis carrinhos de mão; e a "carga" de rapadura, que são trinta rapaduras.

(Trecho da carta de Israel, 2016).

[...] na produção de farinha, essa família usa medidores feitos através de "cabaças", a partir de uma planta que é comum na região.

(Trecho da carta de Gabriel, 2016).

Nessas cartas, notamos tentativas dos alunos de singularizar a Matemática presente nas comunidades em que vivem, oferecendo recursos - como a conversão entre unidades de medida, inclusive mobilizando unidades tradicionais - para que seus leitores possam compreender os saberes matemáticos praticados pelos membros daquele grupo sociocultural. Ainda nessa direção, destacamos a carta da aluna Angélica que, ao contar sobre as práticas de cultivo e processamento da mandioca em sua comunidade e a utilização de uma unidade de medida conhecida por prato, chama a atenção para possíveis incompreensões - no caso, referentes à linguagem - entre os saberes próprios de sua comunidade e aqueles presentes em outros espaços.

Como a maioria das famílias que vivem aqui tem a sua renda baseada no cultivo de mandioca, então encontramos matemática do plantio até o momento da secagem do polvilho, 
que chamamos de goma. É curioso que até na hora que as donas de casa vão medir a goma para fazerem suas receitas que utilizam o produto, elas têm seus métodos. Por exemplo, três litros de goma elas chamam de prato. Se alguém de outro lugar ouvisse falar, certamente iria pensar que seria apenas um prato usado como utensílio doméstico, mas aqui todos conhecem como três litros de goma.

(Trecho da carta de Angélica, 2016).

Além das descrições de saberes matemáticos acima mencionados, surgem nas cartas sutis problematizações sobre o conhecimento matemático e sua relação com o espaço escolar. $\mathrm{O}$ encontro com leituras e discussões que envolvem a etnomatemática parece ter permitido aos alunos reconhecer outros espaços, além e aquém do escolar, nos quais saberes identificáveis como matemáticos são mobilizados. Especialmente em um curso de Licenciatura em Educação do Campo, esse reconhecimento alia-se à valorização dos diferentes saberes e fazeres das comunidades e ao questionamento das práticas de ensino de Matemática vigentes na escola, auxiliando na produção de sentidos para a Matemática, para a educação escolar, para o campo e para o modo de vida camponês.

No meu dia a dia sempre tive contato com situações que envolviam a matemática, mas nunca me dei conta devido aos estereótipos que criei, de que só existe uma matemática, a ensinada na escola, com aquelas fórmulas complicadas e imensas. Mas quando entrei para a universidade percebi o contrário: a matemática pode ser, sim, encontrada em situações simples e rotineiras $[\ldots]$

(Trecho da carta de Michele, 2016).

[...] vejo que a matemática sempre esteve presente na minha vida, tanto que eu nem imaginava, pois na escola a matemática que aprendia era voltada para a preparação para o ENEM [Exame Nacional do Ensino Médio], pouco a ver com os saberes camponeses [...]

(Trecho da carta de Dener, 2016).

Através do curso pude notar que a matemática vai além do que eu havia estudado no meu tempo de escola, pois existe um contexto por trás dela e com isso vimos que a matemática está presente em nosso dia a dia mais do que imaginávamos. [...] Como futuro professor, vejo a importância do aprendizado da matemática na comunidade, não só aquela com regras, mas a matemática contextualizada de acordo com o espaço da comunidade e seus indivíduos.

(Trecho da carta de Saulo, 2016).

Nos trechos acima, presentes nas cartas de Michele, Dener e Saulo são apresentados deslocamentos entre o passado e a atualidade, entre a posição de aluno e a de estudante de uma Licenciatura, futuro professor. Os alunos recordam de práticas escolares nas quais a Matemática aparece estreitamente ligada à técnica, à reprodução e à preparação para os exames: reminiscências de uma Matemática disciplinar que se fez presente nos cotidianos escolares de suas vidas. Contudo, essas recordações são mobilizadas como estratégias para questionar o lugar da Matemática na escola, seja evidenciando-a como desarticulada do modo de vida camponês ou apontando-a como modelo a ser superado no futuro, como professores. Lemos essa dimensão, por exemplo, nas cartas de Josiane, Alcione e Lucina: 
E [o curso] me mostrou que tenho que continuar essa matemática usada pelos meus pais $e$ vizinhos quando estiver com meus alunos e mostrar que o campo pode transformar nossos conhecimentos. [...] algo fantástico que só se aprende no campo.

(Trecho da carta de Josiane, 2016).

Sou filha de pequenos produtores rurais e toda nossa renda é obtida da farinha de mandioca e outros produtos cultivados no nosso pequeno sítio. Antes de estudar matemática, jamais havia pensado que poderia haver matemática na preparação da farinha de mandioca. [...] Esse e outros exemplos são formas de matemática que sempre fizeram parte de minha vida e que eu nunca tinha observado.

(Trecho da carta de Alcione, 2016).

Mas por que muitas pessoas acham estranha a linguagem utilizada pelos camponeses mais antigos, e até mesmo dizem que estão errados? A Educação do Campo vem nos mostrar a resposta para perguntas como essa. $O$ nosso desconhecimento faz com que critiquemos e desvalorizemos os diferentes saberes, sendo que somos sujeitos dessa história. Saberes que deveríamos reconhecer e valorizar.

(Trecho da carta de Lucina, 2016).

A formação de professores por áreas de conhecimento pode contribuir, assim, com uma discussão sobre como produzir nos currículos espaços físicos e subjetivos que permitam inter-relações entre saberes e fazeres, especialmente os científico-acadêmicos, aqueles mobilizados pelas frentes disciplinares, e os populares, imersos nas especificidades das práticas socioculturais de certos grupos. Uma possibilidade seria a abordagem mais direta dos conteúdos da Matemática escolar em afinidade com essas práticas, ganhando, a formação de professores de Matemática e a escola, desenhos curriculares nos quais a centralidade deslocase das classificações produzidas pelos saberes científico-acadêmicos - como disciplinas de Cálculo, Análise, Álgebra e Geometrias - para classificações próprias da Matemática escolar, em seus conceitos, procedimentos e dimensões didático-pedagógicas.

\subsection{Modos de Ser}

A leitura das cartas também nos sensibilizou em diferentes modos de ser que, em uma primeira dimensão, são delineados nas compreensões sobre ser professor de Matemática. Em diferentes momentos, os alunos traçam entendimentos sobre a atuação do professor de Matemática na escola, especialmente em escolas do campo. Nesse sentido, lemos nas cartas de Welison e Marta:

Hoje eu tenho essa de estar fazendo um curso voltado para ser professor da área da matemática na educação do campo, já consigo ter uma visão diferente sobre como ensinar a matemática na escola, penso que o professor tem muitas maneiras de fazer o aluno aprender tal matéria, não só utilizando o quadro negro e o livro, é necessário que o aluno tenha curiosidade, desejo de descobrir o porquê de tal resposta, compreendo que será muito difícil aplicar na sala de aula esse método de ensino, mas ao finalizar esse curso eu pretendo esse 
novo jeito de ensinar, pois sei que é diferente do convencional e com certeza pode agregar muito no aprendizado do aluno.

(Trecho da carta de Welison, 2016).

Tudo foi muito diferente do que eu estava acostumada, principalmente essa nova maneira de encarar e ensinar a matemática. Já estive na sala de aula como professora e confesso que meus métodos eram totalmente voltados para a matemática tradicional. Mas estou aberta a mudanças, conhecer novas ideias e conceitos, produzir e levar a matemática em diferentes contextos socioculturais, valorizando os saberes já existentes que cada sujeito traz de sua bagagem de vida.

(Trecho da carta de Marta, 2016).

É interessante notar que os processos de subjetivação em curso operam não só junto aos alunos que atuaram ou que estão atuando como professores de Matemática, como no caso de Marta, mas também junto aqueles que ainda não atuam como professores. Nesse último caso, como faz Welison, há um olhar intenso para o passado, buscando colocar em movimento antigas compreensões do que é ser professor de Matemática para constituir novas professoralidades.

Esses modos outros de ser professor de Matemática não são expressos apenas em sentidos metodológicos do ensino - como o uso ou não do quadro negro, tido como "tradicional" -, mas também na valorização dos aspectos socioculturais que circunstanciam o espaço escolar. Assim, as novas professoralidades parecem exigir dos alunos um repensar-se como sujeitos do campo, marcando estratégias que questionam não só o lugar da Matemática na escola ou o papel do professor de Matemática no espaço escolar, mas que revisitam o modo de vida camponês em um sentido de novos pertencimentos.

Através desse breve histórico posso dizer que hoje vejo o campo de uma forma melhor, de forma mais agradável, com orgulho de minhas raízes e o quanto é bom morar aqui.

(Trecho da carta de Welison, 2016).

[...] esse curso está me proporcionando uma visão ainda mais ampla do campo, mostrando que todos os saberes são fundamentais em nossa vida. Que os camponeses não devem omitir sua identidade, e nesse contexto me sinto valorizada por fazer parte dessa comunidade ampla de conhecimento, baseada nas experiências e nas diversidades.

(Trecho da carta de Lucina, 2016).

[...] desde que ingressei no curso, aumentei o meu vínculo com a escola da comunidade.

(Trecho da carta de Adriane, 2016).

A perspectiva da área de conhecimento ajuda-nos a pensar essas mudanças na relação do sujeito com o campo, já que acreditamos ser ela portadora de potencialidades que indicam, por um lado, novos caminhos para a articulação entre os saberes populares e os científicoacadêmicos e, por outro, alterações nas condições de vida dos sujeitos do campo. Insinua-se, então, uma dimensão subjetiva do currículo na qual o ser professor de Matemática não 
envolve apenas uma compreensão da Matemática como conhecimento que tem funções e aplicações preestabelecidas no mundo, mas como conhecimento que põe algo a funcionar.

Essa discussão traz contribuições ao propor desenhos curriculares nos quais a Matemática opere não só como ferramenta para o modo de vida camponês, na aplicabilidade de saberes escolares na vida "fora da escola", mas como conhecimento que põe a pensar o modo de vida camponês. Nesse sentido, caberia às dinâmicas curriculares construir espaços nos quais a Matemática figure como elemento que dispara sensibilidades que se movem na direção de diferentes formas de constituir e constituir-se no modo de vida camponês, de maneira que futuros educadores possam implicar-se livre e coletivamente na produção de sentidos do ser professor de Matemática em uma escola do campo.

\section{Considerações finais}

Mudou o meu conceito, o meu jeito de ver minha realidade como camponesa e também mudou o meu jeito de enxergar a matemática, pois até então só conhecia aquela ensinada na escola e aquela usada pelos moradores de minha comunidade nem era levada em consideração. [...] Eu como futura professora de matemática quero valorizar cada vez mais os saberes e fazeres dos sujeitos do campo, com suas diversas matemáticas e mostrando que para ter uma vida de qualidade não é preciso sair do campo.

(Trecho da carta de Rafaela, 2016).

Acreditamos que a fala de Rafaela já seria, em si, uma consideração final para este texto. Por meio de suas cartas, Rafaela e seus colegas, em seus modos de estar, nos permitem pensar questões ligadas à convivência, que fortalece o sentido de coletividade do curso, e à oportunidade de ingresso e permanência no Ensino Superior, denunciando a Licenciatura em Educação do Campo como única possibilidade. Em seus modos de conhecer, Rafaela e seus colegas permitem pensar as diferentes matemáticas que podem ser exploradas a partir de questões socioculturais, bem como o lugar que essas matemáticas podem ocupar no espaço escolar. Finalmente, em seus modos de ser, Rafaela e seus colegas vislumbram profissionalidades junto a trajetórias e a diferentes afetações do curso, desenhando-as não só nas dimensões de ser professor, mas também nas possibilidades de entender e entender-se no modo de vida camponês.

Esses diferentes agenciamentos possibilitam discussões sobre como a perspectiva da formação por áreas de conhecimento estabelece rompimentos com modos tradicionais de conceber e praticar a formação de professores de Matemática, possibilitando a constituição de epistemologias e currículos desenhados na produção de sentidos outros para a educação, para a escola e, fundamentalmente, para a Matemática. Ainda que essas questões sejam recentes, 
acreditamos que elas não se restrinjam à formação de professores de Matemática em Licenciaturas em Educação do Campo, mas que podem reverberar em cursos que se dispõem a formar professores que ensinam Matemática, como a Licenciatura em Matemática ou a Pedagogia, na medida em que se permitam descentralizar a Matemática como linguagem e procedimento fundamental da razão e da verdade, forma legítima de significar o mundo. Isso, contudo, mereceria uma maior atenção e debate.

Por fim, gostaríamos de agradecer aos alunos da habilitação em Matemática do curso de Licenciatura em Educação do Campo da UFMG que, por meio de escritos intensamente comprometidos, que tangem aspectos tão sensíveis de suas vidas, autorizaram a elaboração deste texto com o uso de seus nomes, um modo de reconhecimento e afirmação de suas identidades campesinas.

\section{Referências}

AUAREK, W. A.; PAULA, M. J. Pensar a matemática como área de conhecimento. In: ANTUNESROCHA, M. I.; CARVALHO, C. A. S. (Org.). Caderno IV Escola da Terra: ciências da vida e da natureza e matemática. Belo Horizonte: UFMG, 2016. p. 40-41.

CLARETO, S. M. Terceiras Margens: um estudo etnomatemático de espacialidades em Laranjal do Jari (Amapá). 2003. 254 f. Tese (Doutorado em Educação Matemática) - Instituto de Geociências e Ciências Exatas, Universidade Estadual Paulista "Júlio de Mesquita Filho", Rio Claro, 2003.

CLARETO, S. M. Conhecimento, inventividade e experiência: potências do pensamento etnomatemático. In: FANTINATO, M. C. C. B. (Org.). Etnomatemática-novos caminhos teóricos e metodológicos. Niterói: Universidade Federal Fluminense, 2009. p. 125-134.

D’AMBROSIO, U. Etnomatemática e educação. Educação e Reflexão, Santa Cruz do Sul, v. 10, n. 1, p. 7-20, 2002.

DUARTE, C. G. Relações entre a educação matemática e a educação do campo. In: BRASIL. Secretaria de Educação Básica. Diretoria de Apoio à Gestão Educacional. Pacto Nacional pela Alfabetização na Idade Certa: Matemática. Brasília: MEC/SEB, 2014. p. 21-25.

GOMES, M. L. M. Os 80 anos do primeiro curso de Matemática brasileiro: sentidos possíveis de uma comemoração acerca da formação de professores no Brasil. Boletim de Educação Matemática, Rio Claro, v. 30, n. 55, p. 424-438, ago. 2016.

MARIASH, T. L. Solidariedade por convivência: subjetividade e filosofia do desejo. Lugar Comum, v. 21-22, n. 1, p. 163-184, 2010.

MOLINA, M. C. Expansão das licenciaturas em Educação do Campo: desafios e potencialidade.

Educar em Revista, Curitiba, v. 55, n. 1, p. 145-166, jan./mar. 2015.

PARAÍSO, M. A. Currículo, desejo e experiência. Educação \& Realidade, Porto Alegre, v. 34, n. 2, p. 277-293, mai./ago. 2009.

SOUZA, M. C. R. F.; FONSECA, M. C. F. R. Razão cartesiana, matemática e sujeito: olhares foucaultianos. Educação \& Realidade, Porto Alegre, v. 35, n. 3, p. 303-318, set./dez. 2010. 
Submetido em 27 de Setembro de 2017. Aprovado em 12 de Junho de 2018. 